\title{
A FUNÇÃO DOS ENTES INTERNACIONAIS NO PROCESSO DE DESENVOLVIMENTO - O EXEMPLO DE SÃO PAULO*
}

\author{
THE ROLE OF INTERNATIONAL ENTITIES IN THE DEVELOPMENT PROCESS - THE \\ EXAMPLE OF SÃO PAULO
}

Fernando Dias Menezes de Almeida**

\begin{abstract}
Resumo:
O grande desafio no contexto da globalização é conciliar-se desenvolvimento e redução das desigualdades humanas e sociais. As regiões (entes subnacionais) exercem importante função no processo de desenvolvimento, como vetores de eficiência e harmonização das relações globais. As regiões são mais aptas, do que governos centrais, a conceber políticas de desenvolvimento com visão humana e conectada com a realidade vivida pelos indivíduos. Se uma região pretende inserirse competitivamente na economia globalizada, deve também atuar para resolver as desigualdades de sua área próxima de influência.
\end{abstract}

Palavras-chave: Globalização. Desigualdades humanas e sociais. Economia globalizada.

\begin{abstract}
:
The great challenge in the context of Globalization is to conciliate development and reduction of human and social inequalities. Regions (sub national entities) perform an important role in the process of development, as efficiency pointers and harmonization of global relations. Regions are more suitable than central governments to create development policies with human view and connected to the reality lived by individuals. If a region wants to insert itself competitively in a globalized economy, it will act to solve inequalities of its influence area.
\end{abstract}

Keywords: Globalization. Human and Social Inequalities. Global Economy.

1. O desafio da globalização

Não é objeto deste trabalho aprofundar a investigação, seja do ponto de vista teórico, seja do ponto de vista prático, sobre o fenômeno da globalização, suas causas e seus efeitos. No entanto, pode-se admitir, em formulação bastante singela, ser um efeito virtuoso da globalização um aumento de escala da produção e da riqueza mundial.

Por outro lado, o que se constata é que esse processo tem igualmente levado à concentração da riqueza, no sentido de que, apesar de em regra haver sido ampliado o

\footnotetext{
Texto base para exposição oral na "Troisième session scientifique: La capacité à construire des réponses à la complexité, la montée du niveau regional", do evento "Globalisation et Developpement Territorial", do Conseil Scientifique CRPM do PNUD - Programa das Nações Unidas para o Desenvolvimento.

** Professor Doutor do Departamento de Direito do Estado da Faculdade de Direito da Universidade de São Paulo.
} 
acesso da maioria da população a bens econômicos, mais ainda se ampliou a diferença entre a minoria mais rica e a maioria mais pobre.

Haver diferenças quanto a modos de vida evidentemente não é um mal em si. Não se pode supor a priori que, por exemplo, uma comunidade indígena vivendo no interior da floresta amazônica, conforme seus costumes estabelecidos há séculos, encontrese em uma situação menos desejável do que a comunidade urbana de uma megalópole como São Paulo.

O que é verdadeiramente pernicioso, a partir de uma visão ética e humanista do desenvolvimento, é a diferença que caracterize exclusão, ou seja, a impossibilidade de acesso, por parte de alguns (em regra, de muitos), a determinado padrão de conforto e qualidade de vida entendido, em termos médios, como desejável por uma comunidade.

Esse fenômeno das desigualdades pode ser analisado ao menos em três níveis: a) no nível humano, considerando-se o enorme contingente de excluídos, não importando sua localização ou pertinência geográfica; b) no nível dos países, tomados nas suas relações com outros países, tanto no âmbito mundial, como no âmbito dos seus espaços de integração; c) no nível interno de cada país, confrontando-se regiões (entes subnacionais) mais e menos desenvolvidas.

\section{A função estratégica das regiões}

Tornou-se tranqüila a constatação - de início aparentemente paradoxal - de que a globalização tem o efeito de, ao mesmo tempo, exacerbar nacionalismos e fortalecer regionalismos.

Falando em "nacionalismos", quero me referir ao sentimento de identificação de um grupo, em princípio por critérios históricos, sociais e culturais mais ou menos claros, com a conseqüência da exaltação de suas supostas virtudes e com o intuito de bem marcar sua distinção quanto a outros grupos - no mais das vezes com o intuito de exclusão, ou de explicitar rivalidade.

Já por "regionalismos" quero dizer movimentos de agregação, da busca de formação de entes de abrangência mais ampla, reunindo-se unidades próximas, seja no âmbito interno de um país - este o sentido em que venho usando a palavra "regiões" nesta exposição: entes subnacionais -, seja em seu significado supranacional, reportando-se a espaços de integração nacional, como nos exemplos da União Européia e, de modo mais incipiente, do Mercosul.

Aceitas essas noções, não é difícil constatar que os nacionalismos tendem à dispersão de energia e perda de eficiência e harmonia nas relações globais, enquanto os regionalismos atuam virtuosamente em sentido inverso. 
Particularmente os entes subnacionais podem desempenhar uma função estratégica no processo de desenvolvimento em nível global.

Isso, parece-me, ao menos por duas principais razões: a) a partir da perspectiva regional pode-se adotar uma visão mais humana dos efeitos da globalização; b) as regiões têm maior capacidade de responder a problemas específicos dos indivíduos, estando mais próximas da realidade por eles vivida.

\section{O caso brasileiro}

Isso é bem verdade no caso brasileiro, no qual a dimensão regional apresenta o destaque típico de um Estado organizado como Federação. Aliás, uma Federação peculiar, por considerar que, além dos Estados federados, os Municípios a integram na qualidade de entes dotados de personalidade jurídica e autonomia política. Tem-se assim um Estado federal soberano (República Federativa do Brasil) composto por três níveis de entes autônomos: União, Estados e Municípios.

Essa pluralidade de elementos em nível regional também revela, no Brasil, uma grande desigualdade em termos de desenvolvimento.

Temos assim Estados, como São Paulo, cujos índices de desenvolvimento social e econômico comparam-se aos dos países desenvolvidos da Europa, mas igualmente Estados extremamente carentes. Essa mesma desigualdade apresenta-se no plano dos Municípios.

E aos Estados - tome-se esse exemplo, pois trago aqui a experiência do ponto de vista de um Estado - são atribuídas relevantes competências constitucionais, em boa medida compartilhadas por outros entes federais, tais como nas áreas de ensino, saúde, fomento ao desenvolvimento econômico, ciência, tecnologia, proteção ambiental, transportes, saneamento e energia.

Resta, pois, evidente a importância que os Estados brasileiros possuem para o desenvolvimento do País, valendo ainda destacar que muitas vezes os Estados atuam também diretamente no nível internacional, não no plano das relações diplomáticas privativas do Estado soberano - mas sim no plano da cooperação descentralizada, como bem ilustra a profícua parceria mantida por São Paulo com a Região francesa ProvenceAlpes-Côte d'Azur.

O que se passa, porém, no contexto das desigualdades brasileiras, é que muitos Estados não possuem mínimas condições para o correto desempenho de suas competências. Dependem, assim, substancialmente de ajuda do governo central, o que, na prática, compromete até mesmo sua autonomia, com graves danos para a integridade da federação, além de importar perda de eficiência e competitividade da economia nacional. 
A harmonização interna do desenvolvimento nacional surge, desse modo, internamente, como condição para que os Estados federados possam efetivamente gozar de sua autonomia e, externamente, como instrumento de ganho de competitividade para que o País possa se inserir competitivamente na realidade global.

O Estado de São Paulo, por ser o Estado mais desenvolvido da Federação, tem naturalmente atuado no sentido de impulsionar o desenvolvimento nacional.

Um trabalho que revela exemplarmente esse esforço é o que tem seus resultados apresentados no relatório que gostaria brevemente de expor ${ }^{1}$ e que se encontra na íntegra no endereço eletrônico <http://www.seade.gov.br/produtos/mmilenio/menu.htm>.

Trata-se do relatório de acompanhamento do atendimento, por São Paulo, das metas estabelecidas, no âmbito da Organização das Nações Unidas, quanto aos Objetivos de Desenvolvimento do Milênio. Aliás, esse relatório, divulgado em 2005, foi elogiado e reconhecido pelo Programa das Nações Unidas para o Desenvolvimento (PNUD) como o primeiro relatório de acompanhamento de nível subnacional a ser elaborado, considerados todos os países comprometidos.

\section{Encerramento}

Com esses exemplos, baseados na experiência paulista face aos Objetivos de Desenvolvimento do Milênio, gostaria de fixar a idéia de que as ações que visem ao desenvolvimento, no mundo globalizado, só farão sentido se seus resultados propiciarem melhorias para a humanidade em geral, tomada aqui não como uma abstração, mas considerada a concretude dos indivíduos que a compõem.

Enfim, mais do que nunca mostra-se oportuna a mensagem - que particularmente a mim é muito cara e que entendo válida do ponto de vista humanista e não apenas da religião - do Papa Paulo VI, em sua Encíclica Populorum Progressio: "desenvolvimento é o novo nome da paz".

São Paulo, dezembro de 2008.

\footnotetext{
1 Não transcrevo nesta versão escrita os tópicos verbalmente destacados na exposição, a partir de gráficos e tabelas contidos no referido relatório.
} 